\title{
An PSO Algorithm for Multi Objective Optimization of Multi-Echelon Supply Chain Network Architectures
}

\author{
Rajeshwar $\mathrm{SK}^{1^{*}}$, Latha Shankar $\mathrm{B}^{1}$, Nagaraj PM ${ }^{1}$ and Jason $\mathrm{CHC}^{2}$ \\ ${ }^{1}$ Department of Industrial Engineering \& Management, Siddaganga Institute of Technology, Tumkur 572103, Karnataka, India \\ ${ }^{2}$ Graduate School of Business, Gonzaga University, Spokane, WA, USA
}

"Corresponding author: Rajeshwar SK, Department of Industrial Engineering \& Management, Siddaganga Institute of Technology, Tumkur 572103, Karnataka, India, Tel: 0816221 4001; E-mail: rajeshwarkmath@yahoo.com

Received date: April 29, 2016, Accepted date: May 01, 2016, Published date: May 07, 2016

Copyright: @ 2016 Rajeshwar SK, et al. This is an open-access article distributed under the terms of the Creative Commons Attribution License, which permits unrestricted use, distribution, and reproduction in any medium, provided the original author and source are credited.

\begin{abstract}
Single objective decision models are sufficient for some decision making processes, but there are many situations, where the decisions depend upon multiple objectives. Present the multi objective analysis of the multistage multi echelon production-inventory-distribution supply chain networks different sets of objectives. The performance analysis is performed using weighted sum approach, and trade-off solutions between the sets of objectives are proposed for managerial decision making we have developed An PSO Algorithm for Multi Objective Optimization of Multi-Echelon Supply Chain Network Architectures.
\end{abstract}

Keywords: Multi-objective; PSO; Multi-echelon; Supply chain

\section{Introduction}

A single objective mathematical programming models are commonly used in many managerial and operational decision making processes .Although single objective decision models are sufficient for some decision making processes, but there are many situations, where the decisions depend upon multiple objectives [1]. An important issue in real world supply chain management problem is how to measure the performance of a supply chain for a given set of decision variables, when involving several incommensurable and competing objectives. No matter how appropriate the methodology, if the performance measure is poor, the results could be misleading or false.

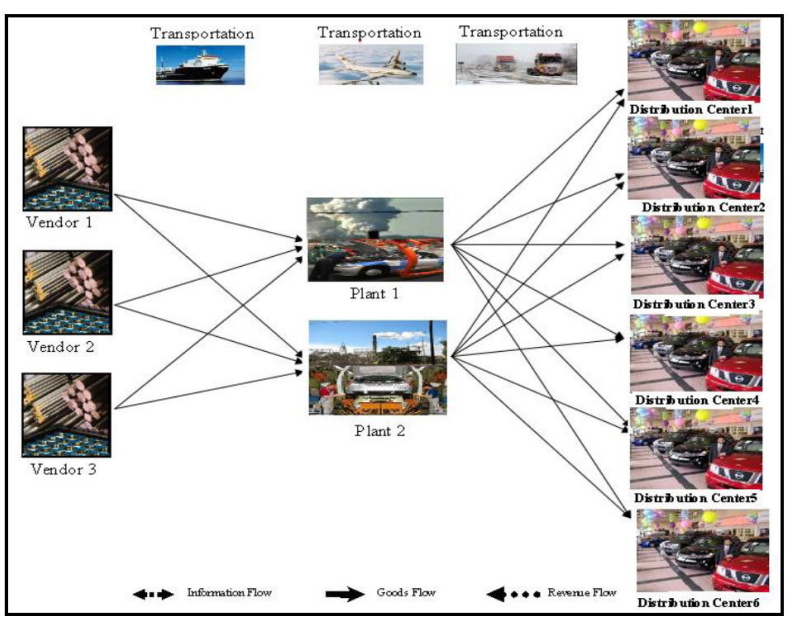

Figure 1: Three echelon supply chain network architecture.
In this chapter, we have considered three stage multi echelon supply chain network problems for the study. Each supply chain network problem is attempted with different sets of conflicting objectives with outstanding new intelligent NLIW-PSO algorithm as solution methodology [2].

\section{Multi objective problem formulation for three stage multi echelon supply chain network}

This section, specifically deals with the modeling of multi objective optimization of a three-stage supply chain network using the Nonlinear inertia weight particle swarm optimization (NLIW-PSO) algorithm with weighted sum approach. The same model assumptions and parameters used in the three echelon SCN are considered in the mathematical formulation of three stage multi-objective SCN (Figure $1)$.

\section{The mathematical formulation of multi-objective three stage multi echelon supply chain architecture}

This study considers the same assumptions, model parameters and the mathematical model of the three stage multi echelon supply chain network architecture (equations 3.1 to 3.4 and constraints equations 3.7 to 3.10 of chapter 3 ) to quantify the relationship among all the decision variables involved in supply chain network. Two sets of conflicting objectives, the total supply chain operating Cost (TSCC) and ratio of Total Manufacturing Cost (TMC) to Total Supply Chain operating Cost (TSCC) are considered as the performance indicators. The problem of optimizing the supply chain configuration can be summarized in the following mathematical model [3].

\section{Objective functions}

Set 1:

Objective Function 1: Minimize TSCC 


$$
\begin{aligned}
T S C C= & {\left[\sum_{c} \sum_{v} \sum_{p}\left(C S_{c, v} \times X_{c, v, p}\right)\right]+} \\
& {\left[\sum_{\mathrm{p}}\left\{\left(\mathrm{MC}_{\mathrm{p}}\right) \times\left(\sum_{\mathrm{d}} \mathrm{Y}_{\mathrm{p}, \mathrm{d}}\right)\right\}+\sum_{\mathrm{p}}\left\{\left(\mathrm{IC}_{\mathrm{p}}\right) \times\left(\sum_{\mathrm{c}} \mathrm{I}_{c, \mathrm{p}}\right)\right\}\right]+} \\
& {\left[\sum_{c} \sum_{v} \sum_{p}\left(X_{c, v, p} \times S T C_{c, v, p}\right)+\sum_{p} \sum_{d}\left(Y_{p, d} \times P T C_{p, d}\right)\right] }
\end{aligned}
$$

Velocity,

$v_{k d}^{\text {new }}=w_{i t e r} \times v_{k d}+c_{1} \times\left[r_{1} \times\left(P_{k d}-X_{k d}\right)\right]+c_{2}$

$\times\left[r_{2} \times\left(G_{d}-X_{k d}\right)\right]$

Objective Function 2: Minimize TMC/TSCC

$$
\frac{T M C}{T S C C}=\frac{\left[\sum_{\mathrm{p}}\left\{\left(\mathrm{MC}_{\mathrm{p}}\right) \times\left(\sum_{\mathrm{d}} \mathrm{Y}_{\mathrm{p}, \mathrm{d}}\right)\right\}+\sum_{\mathrm{p}}\left\{\left(\mathrm{IC}_{\mathrm{p}}\right) \times\left(\sum_{\mathrm{c}} \mathrm{I}_{c, \mathrm{p}}\right)\right\}\right]}{\left\{\begin{array}{l}
\left.\sum_{c} \sum_{v} \sum_{p}\left(C S_{C, v} \times X_{c, v, p}\right)\right]+ \\
{\left[\sum_{\mathrm{p}}\left\{\left(\mathrm{MC}_{\mathrm{p}}\right) \times\left(\sum_{\mathrm{d}} \mathrm{Y}_{\mathrm{p}, \mathrm{d}}\right)+\sum_{\mathrm{p}}\left\{\left(\mathrm{IC}_{\mathrm{p}}\right) \times\left(\sum_{\mathrm{c}} \mathrm{I}_{c, \mathrm{p}}\right)\right\}\right]+\right.} \\
{\left[\sum_{c} \sum_{v} \sum_{p}\left(X_{c, v, p} \times S T C_{c, v, p}\right)+\sum_{p} \sum_{d}\left(Y_{p, d} \times P T C_{p, d}\right)\right]}
\end{array}\right\}}
$$

A justification for using these objective functions is as follows. Minimizing the total operating cost is an important performance metric in supply chain management problems. The second objective function denotes minimizing the ratio of manufacturing costs to total operating cost.

\section{Multi Objective Optimization Multi Echelon Supply Chain Network Architecture Using NLIW-PSO Algorithm}

This section discusses particle representation, velocity calculation of all PSO algorithms, general structure of optimization, experimental design and results and discussions of three stage and four stage multi objective multi echelon supply chain network optimization [4].

\section{Particle representation of four echelon SCN configuration in PSO algorithm}

One solution in a three echelon supply chain network configuration is represented by a particle i.e., one string of integers (decision variables). Three stage multi echelon supply chain network configuration considered in this study is represented by a particle which consists of 30 segments. Similarly, one solution in a four stage multi echelon supply chain network configuration is represented by a particle i.e., one string of integers (decision variables). Four echelon supply chain network configuration considered in this study is represented by a particle which consists of 42 segments [5].

\section{Velocity calculation and position updating equations used for optimization of four echelon SCN architecture}

The NLIW-PSO variants used in this research study have been briefly explained in the section 1.6 of chapter 1 . Following are the equations of NLIW-PSO variant used for velocity calculation and position updating of particles of PSO. $w_{\text {iter }}=\left\{\frac{\left(\text { iter }_{\text {max }}-\text { iter }\right)^{n}}{\left(\text { iter }_{\text {max }}\right)^{n}}\right\}\left(w_{\text {initial }}-w_{\text {final }}\right)+w_{\text {final }}$

$w_{\text {final }}=w_{\text {initial }}+m \times$ iter $_{\max }$

$m=\frac{\left(w_{\text {initial }}-w_{\text {final }}\right)}{\text { iter }_{\max }}$

$X_{k d}^{n e w}=X_{k d}+v_{k d}^{n e w}$

\section{Multi objective PSO algorithm for multi-echelon SCN problem}

General procedural steps involved in multi objective analysis using PSO algorithm with weighted sum approach is given below (Figure 2).

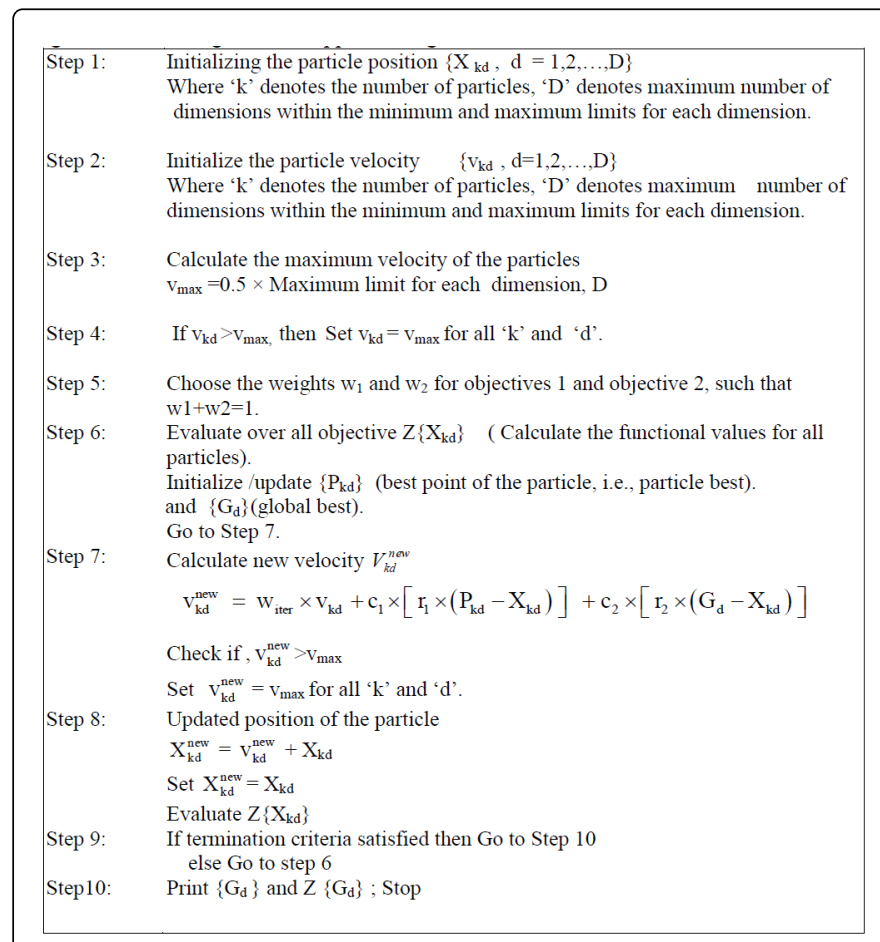

Figure 2: Multi objective PSO algorithm for multi echelon SCN. 
Page 3 of 3

\section{Input data required for the supply chain model}

1. Input data related to vendors, manufactures ware houses and distribution centers for analysis of three and four stage echelon supply chain network architectures

2. The same data sets are considered for the multi objective performance analysis SCN architectures.

3. For four stage multi echelon SCN analysis, we require additional information regarding average monthly demand at each distribution centers and average monthly demand (i.e. one period ) occurring at all the warehouses from the various distribution centers for one year

4. The average lead time required to replenish the goods from the different plants to the warehouses considered.

5. Also the value of ' $\mathrm{Z}$ ' corresponding to the service level is provided in the Table 1 .

\begin{tabular}{|c|c|c|c|c|c|c|c|}
\hline \multirow[t]{2}{*}{ S. No. } & \multicolumn{2}{|c|}{ Weights for objectives } & \multirow{2}{*}{$\begin{array}{l}\text { Best } \\
\text { fitness } 1\end{array}$} & \multirow{2}{*}{$\begin{array}{l}\text { Best } \\
\text { fitness } 2\end{array}$} & \multirow[t]{2}{*}{ Overall objective } & \multirow{2}{*}{$\begin{array}{l}\text { Objective } 1 \\
\text { TMC/TSCC }\end{array}$} & \multirow{3}{*}{$\begin{array}{l}\text { Objective } 2 \\
0.71123\end{array}$} \\
\hline & $\mathbf{w}_{1}$ & $\mathbf{w}_{2}$ & & & & & \\
\hline 1 & 0.1 & 0.9 & 0.896485 & 0.846702 & 0.85168 & 1344727 & \\
\hline 2 & 0.2 & 0.8 & 0.941887 & 0.831171 & 0.853314 & 1412830 & 0.698184 \\
\hline 3 & 0.3 & 0.7 & 0.889595 & 0.847573 & 0.860179 & 1334392 & 0.711961 \\
\hline 4 & 0.4 & 0.6 & 0.870228 & 0.864839 & 0.866995 & 1305342 & 0.726465 \\
\hline 5 & 0.5 & 0.5 & 0.874051 & 0.863394 & 0.868723 & 1311077 & 0.725251 \\
\hline 6 & 0.6 & 0.4 & 0.800067 & 0.921406 & 0.848603 & 1200101 & 0.773981 \\
\hline 7 & 0.7 & 0.3 & 0.831129 & 0.89469 & 0.850198 & 1246694 & 0.75154 \\
\hline 8 & 0.8 & 0.2 & 0.815808 & 0.909032 & 0.834453 & 1223712 & 0.763587 \\
\hline 9 & 0.9 & 0.1 & 0.784989 & 0.932937 & 0.799784 & 1177483 & 0.783667 \\
\hline
\end{tabular}

Table 1: Performance evaluation-MOA of three stage SCN for TSCC and TMC/TSCC.

\section{Results and Discussions of Particle Swarm Optimization Algorithm}

This subsection discusses and summarizes the results of the test problem considered. For the specified maximum number of iterations 15 simulation experiments are carried out to evaluate objective function values for each set weights of $\mathrm{w}_{1}$ and $\mathrm{w}_{2}$ [6]. An experiment is carried out to determine the tradeoff solutions considering the weighted objective for four stages SCN, which was subjected to constraints as defined earlier.

\section{Conclusion}

An attempt is made to solve a two objective integer programming constrained supply chain network problem model. Since there is no well accepted Operation Research Technique to find the optimum solutions for such multiple objective combinatorial optimization problems. Non Linear Inertia Weight PSO algorithm with penalty function approach is used for solving constrained multi-objective supply chain network problem. The experimental results shows that the new algorithm produces better quality trade off near optimal solutions for stated set of objectives for three stage and four stage multi echelon supply chain network architecture.

\section{References}

1. Current J, Min H (1986) Multi-objective design of transportation networks: Taxonomy and annotation. Eur J Oper Res 26: 187-201.

2. Current J, Min H, Schilling D (1990) Multi-objective analysis of facility location decisions. Eur J Oper Res 49: 295-307.

3. Dasci A, Verter V (2001) A continuous model for production distribution system design. Eur J Oper Res 129: 287-298.

4. Daskin MS, Stern E (1981) A Hierarchical Objective Set Covering Model for EMS Vehicle Deployment. Transportation Science 15: 137-152.

5. David Schaffer J (1985) Multiple objective optimization with vector evaluated genetic algorithms. Proceedings of the First International Conference on Genetic Algorithms, pp: 93-100.

6. Deb K (2000) Optimization for Engineering Design: Algorithms and Concepts. Prentice Hall (India). 